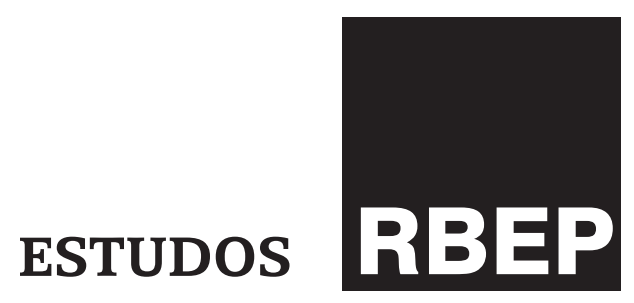

\title{
Políticas públicas complementares para a inclusão social: uma análise do Pré-Vestibular Social
}

Maria Durvalina Fernandes Bastos

Maria de Fátima Cabral Marques Gomes

Lenise Lima Fernandes

Bruno Alves de França

\section{Resumo}

Examina o papel do Pré-Vestibular Social (PVS) da Fundação Centro de Ciências e Educação Superior a Distância do Estado do Rio de Janeiro (Cecierj) para inclusão educacional no conjunto das políticas afirmativas que visam democratizar o ingresso da população de baixa renda no ensino superior. Retoma-se a literatura sobre o tema e, mediante a análise do PVS e do perfil da população atendida, discutem-se problemas relacionados às condições de mobilidade da população de baixa renda e à distribuição desigual de bens e serviços no território, destacados como alguns dos principais desafios para o alcance do objetivo maior do PVS. Apesar dos obstáculos, os resultados alcançados apontam o aumento do ingresso, na universidade, de pessoas do interior e de baixa renda do Estado do Rio de Janeiro.

Palavras-chaves: pré-vestibular; inclusão social; ação afirmativa; mobilidade; interiorização do ensino superior. 


\section{Abstract \\ Complementary public policies for the social inclusion: an analysis of the Social SAT preparation classes}

This article examines the role of the Pré-Vestibular Social (PVS - Social SAT preparation classes), used by the Fundação Centro de Ciências e Educação Superior a Distância do Estado do Rio de Janeiro (Cecierj) for educational inclusion in the set of affirmative action policies seeking the democratization of the low-income population entry in higher education. Revisiting the literature on the subject and, through the analysis of the PVS and the profile of the students, we discuss the problems related to the conditions of the mobility of low income population and to the unequal distribution of assets and services in the territory, highlighting them as some of the main challenges posed to the reach of the PVS's higher purpose. Despite the obstacles, the results achieved point to the increase of university admission rates for low income people and for students originating from the interior of Rio de Janeiro State.

Keywords: Pré-Vestibular; social inclusion; affirmative action; mobility; higher education interiorization.

\section{Introdução}

A educação tem sido considerada propulsora do desenvolvimento socioeconômico e elemento essencial na construção do processo civilizatório. No Brasil, a Constituição Federal (1988) e a Lei de Diretrizes e Bases da Educação Nacional (1996) apontam a promoção da inclusão educacional como elemento componente da nacionalidade, reconhecendo-a como direito de todos, independentemente de etnia, gênero, idade, condições econômicas, sociais, físicas e mentais. Embora o direito à educação seja constitucionalmente reconhecido a todos os cidadãos brasileiros, a igualdade no acesso a ela não se verifica para diferentes segmentos da população. São identificadas defasagens que ocorrem no próprio processo educativo, com distanciamentos dos padrões socialmente reconhecidos como desejáveis para a formação do ser social no campo educacional. Nota-se a existência expressiva de analfabetos e a persistência de elevada defasagem na relação idade/série, o que compromete a ascensão ao ensino médio na idade adequada, contribui para a baixa frequência no ensino universitário e restringe as oportunidades de acesso à educação profissional de nível técnico. As desigualdades e contradições assim desencadeadas potencializam novas distorções que, quando não revertidas, aprofundam ainda outras situações de exclusão social. 
Embora análises do Instituto de Pesquisa Econômica Aplicada (Ipea) tenham apontado que a taxa de frequência líquida no ensino superior cresceu 123\% entre 1996 e 2007, apenas 13\% de jovens na faixa etária dos 18 aos 24 anos tinham acesso a esse nível de ensino em 2007 (Castro, Aquino, Andrade, 2009), tendo avançado até 2009 para 14,4\% (Ipea, 2010). Esse índice se revela muito abaixo da meta de 30\% estipulada para 2011 no Plano Nacional de Educação (PNE). Consideradas as variáveis renda, localização do município e condição raça/cor em 2009, as diferenças no País se mostraram marcantes na faixa de 18 a 24 anos. A taxa de escolarização líquida no ensino superior oscilava entre 7,9\% para os jovens mais pobres e 52,7\% para os mais ricos. ${ }^{1}$ Quanto à localização, $18,2 \%$ dos jovens residentes em áreas metropolitanas frequentavam o ensino superior e somente 4,3\% dos jovens moradores de áreas rurais o faziam. Ainda nessa faixa etária, a taxa de frequência líquida de jovens brancos era duas vezes e meia maior do que dos jovens negros, sendo $21,3 \%$ e $8,3 \%$, respectivamente (Ipea, 2010).

Os entraves que marcam as possibilidades de ingresso e os fluxos escolares do ensino fundamental e médio colaboram para a baixa inserção dos jovens de 18 a 24 anos no ensino superior, indicando claras limitações na viabilização dos direitos constitucionais sugeridos para essa área da vida social.

As distinções socioeconômicas não se revelam apenas nas taxas de acesso à universidade por faixa de renda, mas também no peso desta variável no que tange à composição dos perfis encontrados nos diferentes cursos. Com base em dados do Inep/ENC de 2003, Carvalho e Grin (2004) mostraram que 38\% dos formados em medicina no País naquele ano pertenciam à faixa de renda de mais de 20 salários mínimos, enquanto apenas $7 \%$ estavam na faixa de renda de até três salários mínimos. Os autores observaram ainda que, nas licenciaturas, os dados se invertiam, visto que nestas havia maior percentual de alunos com baixa renda. Assim, afirmam: "é necessário distinguir sempre o curso de que se está falando. Pode-se dizer mesmo que o problema não é tanto entrar na universidade pública, mas entrar nos cursos de elite do bacharelado" (Carvalho, Grin, 2004, p. 20).

Essas limitações exigem tratamento especializado e merecem a atenção de políticas afirmativas na área para a inclusão de grupos vulneráveis e promoção de maior igualdade de oportunidades. No entanto, não devemos incorrer no erro de tratar essa questão de forma fragmentada, como um elemento que se separa do amplo conjunto de desigualdades que configuram a diversidade histórica que caracteriza o perfil socioeconômico, étnico e cultural da população brasileira. Como Martins (1997) e Oliveira (2003), consideramos que tais desigualdades materializam contradições inerentes ao modo de produção capitalista, tendo em vista suas especificidades na dinâmica social do País e seus contornos na fase atual da globalização da economia. Assim, entendemos que os problemas relacionados aos obstáculos à democratização do acesso à educação formal no Brasil são expressões de processos e situações simultâneas de inclusão/ exclusão. Isso significa tomar tais processos na amplitude de condições 
sempre relativas, geradas pela distribuição desigual da riqueza (material e imaterial), ao abrigo das regras do capitalismo.

Conforme mencionado anteriormente, os dados relacionados à frequência da faixa etária de 18 a 24 anos no ensino superior indicam que a renda é um fator determinante para o acesso do brasileiro à universidade.

No que tange aos mecanismos institucionalizados para ampliar o acesso ao ensino superior para os segmentos menos favorecidos, o estabelecimento de cotas para alunos de escolas públicas e o Programa Universidade para Todos (ProUni) ${ }^{2}$ têm sido aqueles considerados de maior impacto nos últimos anos. No que diz respeito aos cursos preparatórios gratuitos para a entrada na universidade, várias iniciativas ganham destaque com os Cursos Pré-Vestibulares Comunitários (CPVC) e os ligados ao movimento negro, como o Educação e Cidadania de Afrodescendentes e Carentes (Educafro) e o Pré-Vestibular para Negros e Carentes no Rio Janeiro (PVNC) (Nascimento, Ignácio, Pinheiro, 2004). Essas iniciativas, majoritariamente desenvolvidas sem o aporte de recursos públicos, têm origem nos movimentos sociais de comunidades que atuam, em geral, sob condições objetivas bastante precárias para a escolarização compensatória e ações inclusivas. Afinal, essas iniciativas contam com suportes instáveis do ponto de vista da garantia de continuidade de suas ações. Entre as diversas experiências conhecidas, encontram-se instituições filantrópicas e de grupos da sociedade civil (igrejas, Organizações não Governamentais, movimentos sociais, associações de moradores) que carecem, muitas vezes, de autonomia financeira; operam em espaços físicos cedidos por escolas públicas e privadas em horários alternativos; contam com quadros docentes compostos por profissionais voluntários, estagiários e licenciandos; e desenvolvem propostas pedagógicas geralmente restritas às experiências docentes dos seus colaboradores individuais. Reconhecendo a pertinência dos debates entre competência técnica e compromisso político no âmbito dos CPVCs, Braz de Carvalho (2006, p. 300) destaca que atualmente há a necessidade de "uma reflexão pedagógica mais articulada, seja sobre a formação básica e propedêutica desejável nos CPVCs, seja sobre as iniciativas acadêmicas complementares voltadas à efetiva ação afirmativa de inclusão universitária desses pré-vestibulandos".

Na tentativa de oferecer um curso preparatório para as provas de acesso à universidade, de natureza pública, gratuita e de qualidade, com uma estrutura pedagógica diferenciada, criou-se, em 2003, o Pré-Vestibular Social (PVS) do Centro de Ciências e Educação Superior a Distância do Estado do Rio de Janeiro (Cecierj), com o objetivo de ampliar e interiorizar o acesso à formação universitária, sobretudo para a população que, inicialmente, apresentou dificuldades para a aprovação nos vestibulares do Consórcio do Centro de Educação Superior a Distância do Estado do Rio de Janeiro (Cederj) à época de seu lançamento, buscando contribuir, assim, para a redução das desigualdades educacionais entre áreas metropolitanas e rurais.

De fato, a política de interiorização do ensino superior almejada por meio do Cederj não apresentou frutos de imediato: conforme pode ser
${ }^{2} \mathrm{O}$ ProUni tem como finalidade a concessão de bolsas de estudo integrais e parciais em cursos de graduação e sequenciais de formação específica em instituições privadas de educação superior. Criado pelo governo federal em 2004 e institucionalizado pela Lei $\mathrm{n}^{\circ} 11.096$, de 13 de janeiro de 2005, oferece, em contrapartida, isenção de alguns tributos àquelas instituições de ensino que aderem ao Programa. 
observado na Tabela 1, em alguns casos, nenhum morador de municípios com Polo Cederj foi aprovado em 2003/2 nos cursos universitários oferecidos e instalados nessas localidades.

Tabela 1 - Município de Residência de Alunos Aprovados no Vestibular Cederj, em 2003/2, com relação ao Município do Polo

\begin{tabular}{|l|c|c|c|c|}
\multicolumn{1}{|c|}{ Polo } & $\begin{array}{c}\text { Número de } \\
\text { alunos }\end{array}$ & $\begin{array}{c}\text { Mesmo } \\
\text { Município } \\
\text { (\%) }\end{array}$ & $\begin{array}{c}\text { Outro } \\
\text { Município } \\
\mathbf{( \% )}\end{array}$ & $\begin{array}{c}\text { Outro } \\
\text { Estado (\%) }\end{array}$ \\
\hline Itaocara & 10 & 70,00 & 30,00 & - \\
\hline Nova Friburgo & 44 & 61,36 & 38,64 & - \\
\hline $\begin{array}{l}\text { Bom Jesus do } \\
\text { Itabapoana }\end{array}$ & 68 & 55,88 & 8,82 & 35,29 \\
\hline Petrópolis & 100 & 47,00 & 52,00 & 1,00 \\
\hline Cantagalo & 106 & 14,15 & 85,85 & - \\
\hline Piraí & 139 & - & 98,56 & 1,44 \\
\hline São Fidélis & 133 & - & 98,50 & 1,50 \\
\hline São Francisco de & 84 & - & 100,00 & - \\
\hline Itabapoana & 57 & - & 100,00 & - \\
\hline São Pedro da Aldeia & & & & - \\
\hline
\end{tabular}

Fonte: Fundação Cecierj, DRE, 2011

Esses dados, já verificados em edições anteriores do Vestibular Cederj, foram decisivos para que a Fundação Cecierj, que abriga o Consórcio Cederj, publicasse o primeiro Edital do Processo Seletivo de Alunos para o Pré-Vestibular Social, em 2003, com vista a preparar os moradores dos municípios que sediavam os polos de seus cursos de graduação.

Nesse sentido, este artigo analisa a relevância do PVS no contexto das políticas afirmativas que visam democratizar o ingresso no meio universitário, tendo como objetivo ressaltar os desafios relacionados à ampliação dos resultados já alcançados pelo Programa em função das condições e necessidades vivenciadas pelo público atendido. Uma vez que a consecução dos objetivos do PVS pressupõe a ampliação dos investimentos no campo educacional e a melhoria dos processos de gestão e coordenação de outras ações a serem implementadas, enfocaremos: a) o planejamento das ações do PVS em distintas áreas do território do Estado do Rio de Janeiro, reconhecendo que a distribuição desigual de recursos e serviços no espaço somada aos desafios relacionados à mobilidade urbana destaca-se como componente relevante na (re)produção dos diversos processos de segregação socioespacial, expressos na área educacional pela insuficiência e deficiência de equipamentos educacionais que absorvam, sobretudo, a população de baixa renda de determinadas regiões; b) a exposição da estrutura acadêmica e do suporte pedagógico oferecido pelo PVS como resposta a uma demanda específica que carecia da atenção pública até então; c) as particularidades referentes ao desenvolvimento do Programa Pré-Vestibular Social e as indicações que elas nos oferecem no desafio à 
superação das limitações relativas à frequência ao curso, ao repertório cultural e à mobilidade urbana de seus alunos.

\section{O Pré-Vestibular Social no contexto do planejamento estadual no campo da educação: a busca por novas perspectivas}

A iniciativa que deu origem ao PVS fundamentou-se no reconhecimento, por parte do governo do Estado do Rio de Janeiro, da relevância de responder à demanda de ampliar o acesso ao ensino superior, democratizando esse processo entre segmentos de menor poder aquisitivo da população residente no interior do Estado, numa perspectiva de maior inclusão social. Esse desafio evidenciava, no entanto, a confluência imediata das variáveis renda e localização espacial a serem consideradas nas ações a se planejar. Afinal, quanto mais desfavoravelmente vivenciadas essas condições, maior a sua contribuição para o aprofundamento de outras formas e níveis de inclusão social precária.

\section{A interiorização do acesso ao ensino superior no Estado do Rio de Janeiro nas novas diretrizes do planejamento no campo da educação}

As análises que aqui propomos, no que tange aos aspectos de distribuição de recursos e ações no território, tomam como referência o conceito proposto por Milton Santos (1996). Para este autor, as ações e os objetos não podem ser considerados separadamente no espaço geográfico, posto que nele se articulam de modo indissociável. Isso nos permite afirmar que os objetos dispostos no espaço só têm sentido a partir da ação humana, a qual resulta nos objetos e é dialeticamente realizada sobre eles. Conforme Ana Clara Torres Ribeiro (2005, p. 93), estes pressupostos definem o sentido da categoria "território" em Santos "como condensação de ações pretéritas" que "interage com os atores sociais, favorecendo ou negando novas ações". Assim, o espaço se configura, simultaneamente, como "território normado", herdado de gerações passadas, e como "território usado", praticado pelos que o vivem em dado contexto e, por isso, prenhe de novas possibilidades de realização.

De acordo com Santos (2007), entre os distintos componentes que contribuem para a formação do modelo cívico de uma sociedade, dois são essenciais: a cultura e o território. Para que um modelo cívico se defina, faz-se necessário clarificar o modo de vida almejado para toda a sociedade, referenciando, assim, o lugar do indivíduo enquanto ser social e as regras de convivência a serem tomadas como parâmetro entre seus integrantes. Para o autor, o componente territorial exige,

[...] de um lado, a instrumentação do território capaz de atribuir a todos os habitantes aqueles bens e serviços indispensáveis, não importa onde 
esteja a pessoa; e, de outro lado, uma adequada gestão do território, pela qual a distribuição geral dos bens e serviços públicos seja assegurada (Santos, 2007, p. 18).

Portanto, é no território que a cidadania se realiza. Lembramos que a ideia de cidadania no Brasil, assim como em outros países, foi concebida sob a égide da ideologia liberal. Ainda, sua construção atravessou distintos contextos marcados, em função de amplas variações na correlação de forças políticas, por avanços e retrocessos referentes à amplitude do leque de direitos conquistados e relacionados a essa condição. Para além disso, numa sociedade caracterizada por profundas contradições sociais, a igualdade dos cidadãos perante tal conjunto de direitos tende a ocorrer apenas no plano formal, já que o efetivo acesso a eles reproduz as distorções daquelas desigualdades e contradições sociais, que são estruturais. Entre uma variedade de autores que debatem o tema, Telles (1999) avalia que, na realidade, são as condições de inserção do indivíduo no mercado de trabalho que definem sua cidadania, o que contraria o princípio fundamental da universalidade formalizado na Constituição Federal de 1998. Se tomarmos, portanto, a ideia de cidadania no sentido de acesso concreto e efetivo aos direitos públicos, podemos melhor compreender a relação estabelecida por Santos (2007) entre suas condições de realização e os limites ou as vantagens viabilizadas no território para que tal realização ocorra.

Exatamente por isso, Santos (2007) propõe tratar a dimensão territorial como fator ativo de constituição da sociedade, e não como mero reflexo desta. Nesse sentido, não se deve atribuir ao conceito de cidadania um conjunto fechado e estático de direitos ou condições. Historicamente instituída e diversamente experienciada, a cidadania em dada sociedade pode abrigar sob seu rótulo níveis distintos de cidadãos. Santos (2007) chama a atenção ainda para o aprofundamento das desigualdades e das contradições que atravessam esse processo no contexto do neoliberalismo. Segundo ele, os valores destacados no bojo deste projeto político e econômico deslocam a referência do cidadão para o consumidor ou, como se torna comum chamar, para o usuário. Como ressalta esse autor, o processo de socialização capitalista faz com que os produtos de consumo se tornem elementos essenciais de mediação entre as pessoas. Os encontros interpessoais diretos se enfraquecem e, na medida em que aqueles produtos se tornam desigualmente apropriados por uns e outros, as possibilidades de dinamização das inter-relações se esvaziam. ${ }^{3}$

Santos (2007) realça que, conforme esta lógica, há uma relação quase intrínseca entre o valor de um indivíduo e o lugar onde ele vive, já que um dos produtos mais disputados na ciranda do consumo capitalista é a terra e, por consequência, a habitação; entretanto, a localização das pessoas no território é uma condição que se estabelece para além das vontades individuais, pois pesam sobre sua determinação as forças do mercado e as decisões do planejamento governamental.

No âmbito do capitalismo, a moradia é tratada como uma mercadoria associada a uma outra mercadoria, a terra. O acesso à habitação é 
determinado, então, pelo potencial de compra do consumidor. Como em outros países de economia periférica, no Brasil este processo tem ocorrido de forma que exclui grande parte da população. Na medida em que o segmento de baixa renda possui restrito poder de compra, suas possibilidades de moradia se reduzem: nos grandes centros, próximos às áreas melhor providas de equipamentos urbanos, realizam-se predominantemente em locais considerados como assentamentos irregulares e/ou ilegais; nas áreas mais afastadas da cidade, ainda que garantida a posse formal da propriedade, geralmente se concretizam em lugares que carecem de equipamentos, também essenciais para a satisfação de suas necessidades sociais básicas e para a garantia de uma inserção social de qualidade. Em decorrência, portanto, da sobreposição desses processos, o território se torna uma das instâncias de expressão das contradições inerentes às sociedades capitalistas (Ribeiro, 1997).

Santos (2007, p. 141) também chama a atenção para a responsabilidade do Estado como agente fundamental na mediação e contenção das distorções provocadas pelas dinâmicas dos sistemas produtivos, e indica como "dever impostergável" da sociedade e essencialmente do Estado "[...] uma autêntica instrumentação do território que a todos atribua, como direito indiscutível, todas aquelas prestações sociais indispensáveis a uma vida decente que não podem ser objeto de compra e venda no mercado".

Analisando os dados recentemente fornecidos pelo Censo de 2010 do IBGE, Sérgio Magalhães (2010) indica que, enquanto a população aumentou 9\%, o crescimento dos domicílios no País alcançou o índice de $49 \%$ na década, sendo realizado fundamentalmente a partir de esforços e investimentos familiares. Para Sérgio Magalhães, a expansão do parque imobiliário significou a construção de moradias distantes dos grandes centros urbanos, em regiões onde o acesso à terra torna-se mais viável, mas que, ao mesmo tempo, se caracterizam frequentemente pelas "carências de infraestrutura e serviços, inclusive os de transporte e de segurança pública". Também para Santos (2007), a renda aparece como variável determinante na seletividade do espaço. Afinal, na dinâmica econômica que articula produção e consumo,

a produção tende a se concentrar em certos pontos do território com tanto mais força quanto se trate de atividades modernas. O consumo responde a forças de dispersão, mas a seletividade social age como um freio, pois a capacidade de consumir não é a mesma, qualitativa e quantitativamente. (Santos, 2004, p. 21).

Em função de características intrínsecas à urbanização brasileira, parte considerável dos segmentos pauperizados é submetida também à segregação espacial desencadeada pela lógica capitalista, que durou por décadas e ainda predomina, dado um modelo de urbanização com distribuição desigual de equipamentos e serviços públicos e privados no território (Santos, 2004), concentrados e melhor ofertados em áreas mais valorizadas da cidade. ${ }^{4}$
${ }^{4}$ Sobre diferentes aspectos dessa dinâmica, ver Kowarick (1979) e Ribeiro (1997), entre outros. 
${ }^{5}$ Segundo Harvey (1992), a reestruturação produtiva se apoia na flexibilidade dos processos de trabalho, dos mercados de trabalho, dos produtos e dos padrões de consumo. Optando pela descentralização espacial, a acumulação flexível interfere nos antigos padrões do desenvolvimento desigual tanto entre setores como entre regiões geográficas, movimentando sob outra lógica o setor de serviços e os conjuntos industriais em diversas regiões, inclusive aquelas até então subdesenvolvidas.
Se são compreensíveis quando identificamos a preponderância das leis do mercado como elemento que essencialmente as desencadeia, tais discrepâncias se tornam aviltantes quando tomadas como propiciadas também pela ineficiência do aparato público que deveria corrigi-las mediante ações fundadas em princípios sociais que devem ultrapassar as exigências do lucro, evitando, assim, que os "pobres de recursos" se transformem em "prisioneiros do lugar" (Santos, 2007). Para a maior parte dos habitantes da cidade, usufruir desses equipamentos e serviços depende de suas possibilidades efetivas de mobilidade no território.

Os serviços educacionais hoje disponibilizados para a população brasileira não são distribuídos por dinâmica distinta da que acabamos de retratar. Entendendo o conhecimento adquirido por meio da educação como um dos maiores bens socialmente produzidos, acreditamos que a democratização do acesso a ele, em todos os níveis, torna-se condição essencial para a efetiva inclusão social dos segmentos mais pobres da sociedade, numa perspectiva emancipatória, exigindo a mobilização de ações e recursos distintos que vão além dos limites desse campo específico.

O PVS deve ser entendido, então, como uma das iniciativas que, a partir da década de 1990, seguem a tendência de um planejamento caracterizado pela busca de melhor distribuição de recursos públicos e privados no espaço, que simultaneamente acompanha e dá suporte às transformações recentes da organização produtiva em curso. ${ }^{5}$

Nessa linha, investimentos foram realizados pelos últimos governos no Estado do Rio de Janeiro na área do ensino superior, sendo quatro as iniciativas destacadas por Wanderley de Souza (2005). A primeira, em 1993, refere-se à criação da Universidade Estadual do Norte Fluminense Darcy Ribeiro (Uenf), instalando um importante polo de ciência e tecnologia na região norte do Estado. A segunda iniciativa diz respeito à criação, em 2001, do Cederj. Vinculado à Fundação Centro de Ciências e Educação a Distância do Rio de Janeiro (Cecierj), foram articuladas, através da metodologia à distância, as universidades públicas localizadas no Estado do Rio de Janeiro (Uerj, Uenf, UFRJ, UFRRJ, Unirio e UFF), ampliando a oferta de vagas no ensino público, gratuito e de qualidade. Buscava-se, ao mesmo tempo, beneficiar os moradores do interior do Estado - que enfrentavam condições limitadas de mobilidade no território do Estado - e alargar as possibilidades de formação de professores para o ensino médio. A terceira iniciativa contempla a ampliação da participação da Fundação de Apoio à Escola Técnica (Faetec) para a área do ensino superior, numa experiência com o Instituto Superior de Educação do Rio de Janeiro, criado em 1998 em várias unidades no interior do Estado. A quarta iniciativa contempla a criação do Centro Universitário da Zona Oeste (Uezo), constituído por institutos superiores para as áreas da Educação, Tecnologia da Informação, Polímeros, Siderurgia, Biotecnologia, Fármacos e Construção Naval, em franca expansão no Estado. Essas iniciativas visam minorar as desigualdades em relação à distribuição de recursos e equipamentos no Estado do Rio de Janeiro, contribuindo, dessa maneira, para maior inclusão dos segmentos mais pobres e com menor acesso a essa infraestrutura. Embora as desigualdades na distribuição de recursos e serviços 
no Estado - também observadas na maior parte das demais regiões do País constituam problemas a serem enfrentados para a democratização do acesso à universidade, atuar exclusivamente sobre essa condição é insuficiente para que se possa alcançar tal objetivo.

No contexto das contradições sociais do sistema educacional brasileiro e a despeito da escassez de suporte material, segmentos das camadas mais desprovidas da sociedade já se organizavam buscando alternativas para superar as deficiências acumuladas ao longo de sua formação nos ciclos fundamental e médio que incidem diretamente na viabilização de seu acesso à universidade pública.

No âmbito estadual temos a iniciativa pioneira do PVS, criado em junho de 2003 e alavancado pelo reconhecimento de duas necessidades articuladas: de um lado, a premência de proporcionar uma resposta institucional à demanda para o oferecimento de um serviço voltado para a continuidade do processo de instrução e formação da população menos favorecida do Estado; de outro, o reconhecimento da importância de implantar uma ação pública nessa área, mediante melhor atuação do planejamento público educacional, dinamizando a oferta e o acesso a esse serviço no território estadual. Nesse sentido, o PVS parte do pressuposto de que o acesso à universidade amplia as possibilidades de inserção no mercado de trabalho e contribui para a melhoria das condições de vida. Considerando a universidade como espaço fundamental de transmissão de valores e ideias, essa experiência visa ampliar os horizontes e as perspectivas de cidadania e ser uma "chance para os excluídos" (Souza, 2006).

Optando por estruturar suas ações mediante a adoção de uma metodologia de ensino mista, parte realizada de forma presencial, parte apoiada na utilização intensiva de tecnologias de ensino a distância (EaD), o PVS desenvolve sua proposta organizando polos de atividade distribuídos no território do Estado do Rio de Janeiro. ${ }^{6}$ Como mostra a Tabela 2, de 2003 a 2010 foi gradativamente ampliado o contingente de polos, municípios e alunos beneficiados, acompanhando e antecipando a própria inserção do Cederj no interior do Estado. Inscreveram-se nesse período 173.238 candidatos e passaram pelo sistema 92.561 alunos.

Tabela 2 - Pré-Vestibular Social (PVS) 2003-2010

\begin{tabular}{|l|c|c|c|c|}
\hline \multicolumn{1}{|c|}{ Ano } & Polos & Municípios & Inscritos & Alunos \\
\hline 2003 & 18 & 18 & 8.897 & 4.818 \\
\hline 2004 & 19 & 19 & 10.574 & 7.218 \\
\hline 2005 & 27 & 23 & 19.599 & 9.400 \\
\hline 2006 & 32 & 25 & 13.474 & 9.156 \\
\hline 2007 & 37 & 27 & 23.460 & 13.515 \\
\hline 2008 & 42 & 32 & 28.040 & 14.451 \\
\hline 2009 & 44 & 34 & 29.710 & 15.744 \\
\hline 2010 & 50 & 37 & 39.484 & 18.259 \\
\hline Totais & 269 & 215 & 173.238 & $\mathbf{9 2 . 5 6 1}$ \\
\hline
\end{tabular}

Fonte: PVS/Banco de Dados de Alunos, 2003-2010.
${ }^{6}$ Dos 50 polos, 39 estão abrigados em dependências de escolas estaduais, seis em escolas municipais e o restante em polos do Cederj. 
Registra-se significativa demanda para a implementação de polos na Região Metropolitana do Rio de Janeiro, em especial na Baixada Fluminense, bem como elevada competição por vaga. Na seleção de alunos em 2010, no município de Nova Iguaçu, houve 2.808 candidatos para 720 vagas, perfazendo uma relação de 3,9 candidatos por vaga. Essa pressão se ameniza com a oferta do curso intensivo no mês de junho, quando parte dessa demanda é atendida.

\section{A Metodologia do curso: organização institucional e pedagógica}

Ao iniciar suas atividades, o PVS oferecia somente aulas de Língua Portuguesa e Matemática, com três horas cada, aos sábados; à medida que apresentou resultados, conquistou espaço institucional e recursos orçamentários, ${ }^{7}$ o Programa incluiu progressivamente novas disciplinas. Assim, foram incorporados os conteúdos de Biologia e Física em 2004, Química e Geografia em 2005, História em 2006 e Redação em 2007. Em 2011, a disciplina de língua estrangeira (Inglês) foi inserida no quadro curricular, a única das disciplinas obrigatórias em vestibulares e no Exame Nacional do Ensino Médio (Enem) que ainda não era oferecida aos alunos desse curso. ${ }^{8}$ A partir de 2011 os alunos do PVS passaram a contar, então, com nove disciplinas.

São oferecidas duas modalidades do curso: o extensivo, que ocorre de março a dezembro, e o intensivo, de junho a dezembro. Um polo padrão do PVS engloba seis turmas de 60 alunos, totalizando 360 vagas. Em 2004, a tentativa de oferecimento das aulas na sexta-feira à noite e no sábado o dia inteiro não foi bem sucedida. O transporte foi o maior empecilho alegado pelos alunos para que não frequentassem as aulas nesses dias, dadas as distâncias que tinham que percorrer para chegar ao polo. Reconhecendo as características e necessidades deste segmento da população, o Programa optou por um único dia na semana para as aulas (o sábado) em 90\% dos polos, diminuindo os custos com transporte para os alunos. Somente em 10\% dos polos as aulas ocorrem duas vezes por semana, à tarde, atendendo não só alunos que cursam o último ano do ensino médio, mas também trabalhadores

${ }^{7}$ O PVS conta com recursos orçamentários do Fundo de Combate à Pobreza do Estado do Rio de Janeiro e, por meio de convênio com a Secretaria Estadual de Educação e Prefeitura, oferece alimentação aos alunos nos polos que funcionam aos sábados.

8 A escolha do Inglês se deve à necessidade e oportunidade de agregar valor à formação do jovem aluno no contexto de possibilidades de trabalho numa economia globalizada em que esta é uma língua largamente utilizada na área de tecnologia da informação. que usam escalas, diaristas, etc. Em 2010 funcionaram 236 turmas em 50 polos.

Conforme mencionado anteriormente, a metodologia de ensino utilizada no curso é mista: parte realizada de forma presencial, parte apoiada na utilização intensiva de tecnologias de ensino a distância (EaD). O aluno dispõe de uma hora de aula semanal para cada disciplina oferecida pelos tutores, com o suporte de material didático gratuito. Essa dinâmica é completada pelo trabalho de tutoria a distância, simulados, exercícios e feedback on-line, de modo a auxiliar o aluno nas dúvidas existentes. A presença dos discentes é registrada pelos tutores nos diários de classe on-line que integram o SisPVS - plataforma que abriga 
também os relatórios semanais dos tutores e dos tutores representantes -, permitindo o controle semanal de frequência em todas as turmas e polos. Assim, viabilizam-se a análise do comportamento do alunado e o planejamento das atividades do curso.

Para dar suporte à dinâmica de ensino-aprendizagem, o PVS oferece a seus alunos a Tutoria a Distância. Esta é disponibilizada para todas as disciplinas através de atendimento telefônico gratuito, sendo constituída de serviço tira dúvidas sobre o conteúdo do material didático e de orientações educativas. Um Sistema on-line - o Sis0800 - de registro dos telefonemas dos alunos foi montado de maneira a possibilitar o controle do número de acessos ao serviço, de sua duração, os temas, as disciplinas e os polos com ligações mais frequentes, funcionando como feedback para os conteúdos ministrados em sala de aula. Dessa forma, cada tutor pode acompanhar pelo sistema a frequência de acesso ao serviço dos alunos de seu polo e as dúvidas apresentadas. Ao longo do curso, são realizados simulados presenciais e a distância, além de exercícios on-line que são corrigidos por tutores de todos os polos. Em 2009, foi implementado ainda o Sistema de Orientação Acadêmica (SOA), em que cada tutor é designado para acompanhar um grupo de alunos. Por meio de contatos diretos, dentro e fora da sala de aula, por e-mail e por sites de relacionamento, o estudante pode ser assistido de forma mais direta e tratar de assuntos tais como a importância da frequência ao curso, a disponibilização de exercícios complementares, informações e orientações sobre carreiras, vestibulares, procedimentos para obtenção da isenção de taxas nos exames, entre outros assuntos relacionados ao PVS.

\section{O acesso à educação superior como mecanismo de ampliação das formas de inserção social: a contribuição do PVS}

\section{O perfil da população atendida}

Na seleção dos alunos para o Pré-Vestibular Social é levada em consideração a situação socioeconômica do candidato e das pessoas residentes no mesmo domicílio. Os candidatos que apresentam renda per capita familiar superior a $\mathrm{R}$ \$ 630,00 (1,5 salário mínimo em valores de 2008) ${ }^{9}$ podem frequentar o curso somente quando há sobra de vagas. O processo seletivo é complementado pela análise do projeto acadêmico ${ }^{10}$ do candidato, apresentado em um texto no qual o aspirante à vaga aborda a sua vida como estudante e tece considerações sobre os seus planos. A Tabela 3 mostra que $87 \%$ dos alunos inseridos no PVS em 2010 apresentavam renda per capita familiar igual ou inferior a $\mathrm{R} \$ 630,00$.

\footnotetext{
9 Em 2008, o salário mínimo correspondia a R\$ 415,00.

${ }^{10}$ Conceição e Cunha (2010) afirmam que esse projeto contrasta com as condições de vida de jovens da periferia urbana, por exemplo. Daí a importância da identificação desse projeto para oferecer suporte à sua realização.
} 


\section{Tabela 3 - Pré-Vestibular Social (PVS) 2010 - Alunos - Renda per capita Familiar}

\begin{tabular}{|c|c|c|c|c|c|c|}
\hline $\begin{array}{c}\text { Faixa de renda } \\
\text { per capita }\end{array}$ & $\begin{array}{l}\text { Número } \\
\text { de alunos } \\
\text { extensivo } \\
2010\end{array}$ & $\%$ & $\begin{array}{c}\text { Número } \\
\text { de alunos } \\
\text { intensivo } \\
2010\end{array}$ & $\%$ & $\begin{array}{l}\text { Número } \\
\text { total de } \\
\text { alunos } \\
2010\end{array}$ & $\%$ \\
\hline$\leq \mathrm{R} \$ 207,00$ & 2.625 & 21 & 1.173 & 20 & 3.798 & 21 \\
\hline $\begin{array}{l}>\mathrm{R} \$ 207,00 \mathrm{e} \\
\leq \mathrm{R} \$ 415,00\end{array}$ & 5.614 & 45 & 2.659 & 45 & 8.273 & 45 \\
\hline $\begin{array}{l}>\mathrm{R} \$ 415,00 \mathrm{e} \\
\leq \mathrm{R} \$ 630,00\end{array}$ & 2.564 & 21 & 1.298 & 22 & 3.862 & 21 \\
\hline$>\mathrm{R} \$ 630,00$ & 1.570 & 13 & 756 & 13 & 2.326 & 13 \\
\hline Total & 12.373 & 100 & 5.886 & 100 & 18.259 & 100 \\
\hline
\end{tabular}

Fonte: PVS/Banco de Dados de Alunos, 2003-2010.

Pode-se questionar a pertinência do uso de tecnologias de ensino a distância num Programa de educação de caráter social que pressupõe o uso de equipamentos de informática, porém é conhecido o fenômeno do avanço do consumo das mídias no Brasil. A internet segue a tendência mundial, tornando-se o veículo utilizado por $46,1 \%$ da população brasileira acima de 16 anos, que navega 16,4 horas semanais, em média. ${ }^{11}$ Conforme o banco de dados de alunos do PVS, em 2010, o acesso à internet não se constituía um obstáculo para este grupo, tal como observamos na Tabela 4. No curso extensivo, 96,67\% dos alunos faziam uso da internet, enquanto no curso intensivo esta taxa era ainda um pouco maior: 97,45\%.

Tabela 4 - Pré-Vestibular Social (PVS) 2010 - Alunos - Acesso à Internet

\begin{tabular}{|c|c|c|c|c|}
\hline $\begin{array}{c}\text { Onde acessa } \\
\text { a internet? }\end{array}$ & $\begin{array}{c}\text { Número } \\
\text { de alunos } \\
\text { extensivo } \\
2010\end{array}$ & $\%$ & $\begin{array}{c}\text { Número } \\
\text { de alunos } \\
\text { intensivo } \\
2010\end{array}$ & $\%$ \\
\hline Em casa & 6.547 & \multirow{5}{*}{96,67} & 2.654 & \multirow{5}{*}{97,45} \\
\hline Lan-house & 4.434 & & 2.088 & \\
\hline Casa de parentes/amigos & 3.476 & & 1.613 & \\
\hline No trabalho & 1.085 & & 508 & \\
\hline Na escola & 1.427 & & 567 & \\
\hline Não usa & 412 & 3,33 & 150 & 2,55 \\
\hline Total & 17.381 & 100,00 & 7.580 & 100,00 \\
\hline
\end{tabular}

Fonte: PVS/Banco de Dados de Alunos, 2003-2010.

Por outro lado, os dados da tabela anterior revelam mais um aspecto

${ }^{11}$ Informações retiradas de pesquisa encomendada pela Secretaria de Comunicação Social da Presidência da República divulgada em fevereiro de 2010 (IG, SP, 17.06.2010). das condições desfavoráveis de inclusão social vivenciadas por essa população. Do total de alunos nos dois formatos de curso, somente 58\% acessavam a rede em sua própria casa. Embora atentos aos avanços tecnológicos, outros $42 \%$ dos alunos ainda precisavam lançar mão de 
alternativas para poderem acessar a internet. Não dispondo desse recurso em suas próprias casas, pelos limites de sua condição socioeconômica, muitos alunos o faziam em lan houses, casa de parentes e amigos, trabalho e escola. Para que o curso utilize instrumentos de educação a distância (EaD) em larga escala, deve-se levar em conta que o acesso para esse fim exige um tempo substancial na utilização do computador. As lan houses, pelos custos e as restrições de uso no trabalho e na escola, assim como o desconforto da utilização em casas de parentes e amigos, tornam-se empecilhos substanciais para que esses alunos do PVS acessem a internet e realizem os simulados e exercícios on-line. Paradoxalmente, a utilização das técnicas de EaD e a internet em suas próprias residências se mostraram potencialmente mais inclusivas para alunos que, por sua condição socioeconômica, têm baixa mobilidade urbana. Por enquanto, as dificuldades de alguns alunos têm sido supridas com horários especiais criados por diretores de polos do Cederj nos laboratórios de informática dessas unidades de ensino.

Pelas características da população atendida, um dos desafios detectados é a permanência no curso. Na Tabela 5 podemos constatar que, 2 meses após o início do curso, 51\% dos alunos que ingressaram no PVS em março apresentam uma frequência às aulas igual ou superior a 75\%; desse total, 40\% pertencem ao grupo de menores de 18 anos, sendo esta faixa etária a que também apresentou o maior percentual de permanência (62\%). Embora minoritário, o grupo de alunos acima de 40 anos, com $11 \%$ de ingresso, comparece com o segundo maior percentual de permanência no curso (52\%).

\section{Tabela 5 - Pré-Vestibular Social (PVS) 2010 - Frequência $\geq 75 \%$ em Maio - Faixa Etária}

\begin{tabular}{|l|c|c|c|c|c|}
\hline & $\begin{array}{c}\text { Número } \\
\text { de alunos } \\
\text { extensivo } \\
\text { Faixa de idade }\end{array}$ & $\begin{array}{c}\text { Número de } \\
\text { (março 2010) }\end{array}$ & $\begin{array}{c}\text { alunos extensivo } \\
\text { com 75\% de } \\
\text { frequência ou } \\
\text { mais em maio }\end{array}$ & $\%$ & $\begin{array}{c}\text { \% na } \\
\text { faixa } \\
\text { etária }\end{array}$ \\
\hline < 18 anos & 4.046 & 33 & 2.493 & 40 & 62 \\
\hline de 18 a 24 anos & 4.207 & 34 & 1.900 & 30 & 45 \\
\hline de 25 a 30 anos & 1.308 & 11 & 500 & 8 & 38 \\
\hline de 31 a 40 anos & 1.523 & 12 & 707 & 11 & 46 \\
\hline$>40$ anos & 1.289 & 10 & 673 & 11 & 52 \\
\hline Total & $\mathbf{1 2 . 3 7 3}$ & $\mathbf{1 0 0}$ & $\mathbf{6 . 2 7 3}$ & $\mathbf{1 0 0}$ & $\mathbf{5 1}$ \\
\hline
\end{tabular}

Fonte: PVS/Banco de Dados de Alunos, 2003-2010.

O mapeamento do perfil dos alunos atendidos pelo PVS e o acompanhamento de sua dinâmica no transcorrer do curso têm sido considerados fator fundamental para se entender melhor a demanda da população à qual o Programa se destina e, simultaneamente, captar os obstáculos à 
ampliação do alcance de seus objetivos. Nesse sentido, parece-nos extremamente preocupante o fato, tal como disposto na Tabela 6, de 56\% dos inscritos que desistiram do curso em maio se encontrarem entre os alunos com até 24 anos; esta é a faixa etária que idealmente deveria estar frequentando os cursos universitários e ser, portanto e preferencialmente, o público-alvo do PVS.

\section{Tabela 6 - Pré-Vestibular Social (PVS) 2010 - Frequência $\leq$ 25\% em Maio - Faixa etária}

\begin{tabular}{|c|c|c|c|c|c|}
\hline Faixa de idade & $\begin{array}{c}\text { Número } \\
\text { de alunos } \\
\text { extensivo } \\
\text { (março 2010) }\end{array}$ & $\%$ & $\begin{array}{c}\text { Número } \\
\text { de alunos } \\
\text { extensivo } \\
\text { com } 25 \% \text { de } \\
\text { frequência } \\
\text { ou menos em } \\
\text { maio de } 2010\end{array}$ & $\%$ & $\begin{array}{c}\text { \% na } \\
\text { faixa } \\
\text { etária }\end{array}$ \\
\hline$<18$ anos & 4.046 & 33 & 356 & 17 & 9 \\
\hline de 18 a 24 anos & 4.207 & 34 & 806 & 39 & 19 \\
\hline de 25 a 30 anos & 1.308 & 11 & 336 & 16 & 26 \\
\hline de 31 a 40 anos & 1.523 & 12 & 318 & 15 & 21 \\
\hline$>40$ anos & 1.289 & 10 & 248 & 12 & 19 \\
\hline Total & 12.373 & 100 & 2.064 & 100 & 17 \\
\hline
\end{tabular}

Fonte: PVS/Banco de Dados de Alunos, 2003-2010.

Coloca-se assim a necessidade de, posteriormente, analisar os motivos que levaram esses alunos a desistirem do curso, sendo esse um dos desafios para o Pré-Vestibular Social. O Programa, partindo dessa constatação, buscou implementar ações, ainda que modestas, para o enfrentamento do problema, conforme explicitado no próximo item.

\section{A mobilização de ações complementares para melhoria das condições de inclusão social}

Além de medidas estritamente acadêmicas, aos poucos foram sendo introduzidas ações complementares consideradas relevantes para a obtenção de melhores resultados com o Programa.

O Sistema de Orientação Acadêmica (SOA) também tem por objetivo direcionar melhor a escolha do curso superior e auxiliar os alunos na busca de alternativas para permanência no Programa. Além disso, é oferecido suporte também para os alunos pleitearem a isenção de taxas dos vestibulares. A oferta de gratuidade da taxa de inscrição no vestibular do Cederj para alunos do PVS que tenham ao menos $75 \%$ de frequência constitui-se outra estratégia de inclusão e fixação de alunos no curso. 
Outras duas ações entendidas como essenciais para o suporte e melhor aproveitamento do PVS dizem respeito à alimentação e ao material didático disponibilizados para os alunos. Na medida em que os alunos do PVS permanecem em horário integral nos sábados, são oferecidos desjejum e almoço, conforme estabelecem os convênios com a Secretaria de Estado de Educação e as prefeituras municipais. Depoimentos dos alunos têm indicado que a alimentação disponibilizada é um fator importante na garantia de sua frequência e permanência no curso. Quanto aos livros didáticos, nos dois primeiros anos eles foram vendidos ao preço simbólico de $\mathrm{R} \$ 1,00$ (um real) e, a partir de 2005, começaram a ser distribuídos gratuitamente. Os alunos recebem dois livros de cada disciplina ao longo do curso.

Também foi valorizado o desenvolvimento da atividade "Troque livros, troque ideias", que objetivou a democratização da leitura por meio da circulação de livros. Sem custos, esse projeto, que depende unicamente da iniciativa de tutores e alunos, frutificou e vem sendo desenvolvido em vários polos.

\section{Os resultados alcançados e a necessidade de ampliação das ações afirmativas complementares para a inclusão social}

\section{As conquistas registradas pelo Programa}

Em termos de desempenho dos alunos, podemos afirmar que o PVS faz diferença no interior do Estado e contribui para que o Cederj cumpra sua missão de interiorizar o acesso ao ensino superior. Conforme a Tabela 1 deste trabalho, no Vestibular Cederj 2003/2, em alguns municípios de diferentes regiões do Estado do Rio de Janeiro que abrigavam polos de Graduação do Cederj, nenhum residente havia sido aprovado. Em compensação, no período de 2006 a 2010, 399 moradores dos mesmos municípios, ex-alunos do PVS, foram aprovados em cursos de graduação do Cederj. Dessa forma, o PVS tem contribuído para a formação de mão de obra local, especialmente professores para o ensino médio em regiões onde essa carência se constitui problema. ${ }^{12}$

No vestibular 2009/2 do Consórcio Cederj, 521 alunos do PVS - 20\% dos que realizaram as provas - ocuparam as vagas da graduação. No Vestibular Cederj 2010/2, 756 alunos do PVS foram aprovados, representando $25 \%$ dos que fizeram as provas, o que significa um aumento de cinco pontos percentuais em relação ao desempenho de 2009. ${ }^{13}$

Em 2010, dos graduandos do Cederj foram alunos do PVS: 42\% dos aprovados para Ciências Biológicas em Nova Friburgo; 35\% dos aprovados para Pedagogia de Nova Iguaçu; 25\% dos aprovados para Matemática de Cantagalo; 20\% dos aprovados para o curso de Administração de Piraí; 16\% dos aprovados para o curso de Administração Pública em Paracambi; 25\% dos aprovados para o curso de Física em Campo Grande; 28\% dos aprovados para o curso de História em Miguel Pereira; 27\% dos aprovados

\footnotetext{
${ }^{12}$ A grande maioria dos cursos de graduação do Consórcio Cederj está na área das licenciaturas.

${ }^{13}$ As informações sobre o desempenho dos alunos do PVS no vestibular Cederj são levantadas graças ao acesso ao banco e cruzamento de dados autorizado pela Comissão do Vestibular daquela Instituição.
} 
${ }^{14}$ Das universidades que com põem o Cederj, somente a Uer e a Uenf estão submetidas à Lei $\mathrm{n}^{\circ} 4.151 / 03$ (alterada pela Lei $\left.n^{\circ} 5.346 / 08\right)$, que instituiu o sistema de cotas nas universidades públicas estaduais do Rio de Janeiro. para o curso de Química em Piraí; 40\% dos aprovados para Tecnologia em Sistemas de Computação em Três Rios; 40\% dos aprovados para o curso de Turismo em Saquarema. Esses dados permitem observar que iniciativas como o PVS abrem reais perspectivas de favorecer o acesso à educação superior de forma mais democratizada e espacialmente desconcentrada. Sua potencialidade parece residir no fato de articular demandas por reconhecimento (na medida em que é elaborada no contexto de políticas de ação afirmativa e questionando a pretensa igualdade de condições dos candidatos nos concursos de acesso à universidade) com demandas por igualdade (na medida em que corresponde à percepção por setores populares da educação superior como instrumento para a mobilidade social).

Além disso, o esforço e as realizações dos alunos do Pré-Vestibular Social se tornam mais valiosos se considerarmos que o critério de ingresso no curso preparatório é a carência socioeconômica e que o acesso aos cursos de nível superior tem como referência o mérito acadêmico. Somente 10\% dos aprovados em 2010 se valeram da Lei de Cotas $^{14}$ no Vestibular Cederj nos cursos da Uerj e da Uenf.

O PVS ainda não conta com um sistema de acompanhamento de seus egressos e depende exclusivamente da informação prestada voluntariamente por seus ex-alunos, medida esta sempre incentivada pelos tutores. No site do curso foi disponibilizada uma página, denominada "Hall dos Aprovados", que registra os depoimentos dos alunos que se propõem a ter suas conquistas tornadas públicas. Dessa forma são registradas aprovações em cursos presenciais de universidades públicas, como a UFF, a Uerj e a UFRJ. Dos aprovados para ingressar em cursos superiores no primeiro semestre de 2011, com base apenas nos alunos que destacaram sua situação nos depoimentos do site do Pré-Vestibular Social, vemos que 89,6\% foram aprovados em instituições públicas (federais e estaduais) nos diversos campos do conhecimento. Nesse número incluem-se os alunos que ingressaram nos cursos do Cederj, totalizando $38,7 \%$. Outros $10,41 \%$ dos alunos foram aprovados em distintas instituições privadas.

Em 2012 será implementado no SOA campos específicos sobre as inscrições nos vestibulares e no Enem, com vista a um eventual cruzamento de bancos de dados para a verificação dos aprovados, caso as outras instituições permitam o acesso aos dados de seus vestibulares.

Os resultados, mesmo que parciais, comprovam tanto a importância quanto a viabilidade de se combinar distintos investimentos no âmbito da educação, fundamentais para a criação ou fortalecimento de políticas públicas nessa área.

Além disso, o domínio de saberes, nesse caso saberes valorizados para o vestibular, confere a esses alunos a sensação de empoderamento pessoal indispensável ao exercício de uma cidadania ativa, ao desenvolvimento de uma atitude protagonista perante a vida. Não obstante os alunos se prepararem para disputar vagas em universidades públicas e privadas, com o aprimoramento que adquirem em Língua Portuguesa, Redação e Matemática, não é raro conquistarem também aprovações 
em concursos públicos, principalmente nas prefeituras municipais no interior do Estado.

A experiência didática vivenciada pelos tutores no PVS também deve ser valorizada. Muitas instituições universitárias reconhecem este trabalho como estágio didático obrigatório, e vários tutores ingressam no curso para obterem a comprovação oficial dessa experiência, que é supervisionada semanalmente pelos coordenadores das disciplinas e sistematicamente controlada pela direção geral. Nesse sentido, o PVS tem contribuído para a urgente necessidade de formação de professores em todo o Estado do Rio de Janeiro, oferecendo a oportunidade de aprimorar os conhecimentos e as práticas sobre a didática educacional.

Por outro lado, a integração entre alunos e professores tem sido fundamental para a consolidação dos objetivos elencados pelo PVS. Na maioria das vezes, os professores são a referência mais próxima de acesso à universidade, já que, no âmbito da família, o convívio com universitários ou graduados em nível superior é raro nessa faixa de renda da população. Os contatos dos alunos com os tutores - jovens adultos, muitos ainda estudantes, exemplos de ascensão social e educacional, boa parte também oriunda de escolas públicas, portadores de visão positiva das suas potencialidades - fortaleceram laços de identificação e os estimularam a elevar seu nível de aspiração e a se organizarem para alcançar os novos objetivos. Com a orientação dos tutores, os alunos são incentivados a conhecer espaços culturais e participar de eventos, contribuindo, assim, para o enriquecimento das experiências culturais desses alunos, geralmente restritas pelos custos financeiros envolvidos.

\section{Os entraves postos pelas condições de mobilidade como desafio à ampliação das conquistas alcançadas}

A despeito da relevância do Programa e de seus resultados, estudos anteriores (Bastos, Gomes, Fernandes, 2010) já apontavam a necessidade de um maior escopo para além dos conhecimentos adquiridos pelos alunos no curso. A abrangência territorial alcançada por cada um dos polos do PVS comprova um dos aspectos mais relevantes na (re)produção das dinâmicas de segregação socioespacial: a relação entre renda, local de moradia e distribuição desigual de recursos e serviços no território. Buscando uma melhor visualização dessa informação, traçamos os fluxos de alunos no Mapa 1, a seguir, identificando os deslocamentos do público atendido nos polos de Campo Grande (KUB), Nova Iguaçu (NIG), Duque de Caxias (PDC-25 de Agosto; CSM-Jardim Primavera) e São Gonçalo (SGO). ${ }^{15}$

A imagem nos permite observar que, em alguns casos, o deslocamento feito pelo aluno exige uma maior capacidade de mobilidade tanto pela distância percorrida quanto pela tendência à menor oferta de alternativa de transporte, especialmente no caso de localidades mais afastadas das áreas centrais da cidade.

\footnotetext{
${ }_{15}$ É importante ressaltar que o aluno, no ato da inscrição, escolhe o polo onde deseja estudar. Caso não seja selecionado, pode realizar uma $2^{a}$ opção. Os deslocamentos apontados nos mapas, via de regra, ocorrem por falta de opção de um polo na região. Os deslocamentos "muito estranhos" podem estar relacionados ao local de trabalho de onde parte o aluno para o curso, o local onde o aluno passa o final de semana ou a indicação de uma futura mudança. A Direção do PVS tem realizado, a pedido e mediante a ocorrência de vaga, transferências de alunos entre os polos justamente para evitar grandes deslocamentos dos alunos.
} 

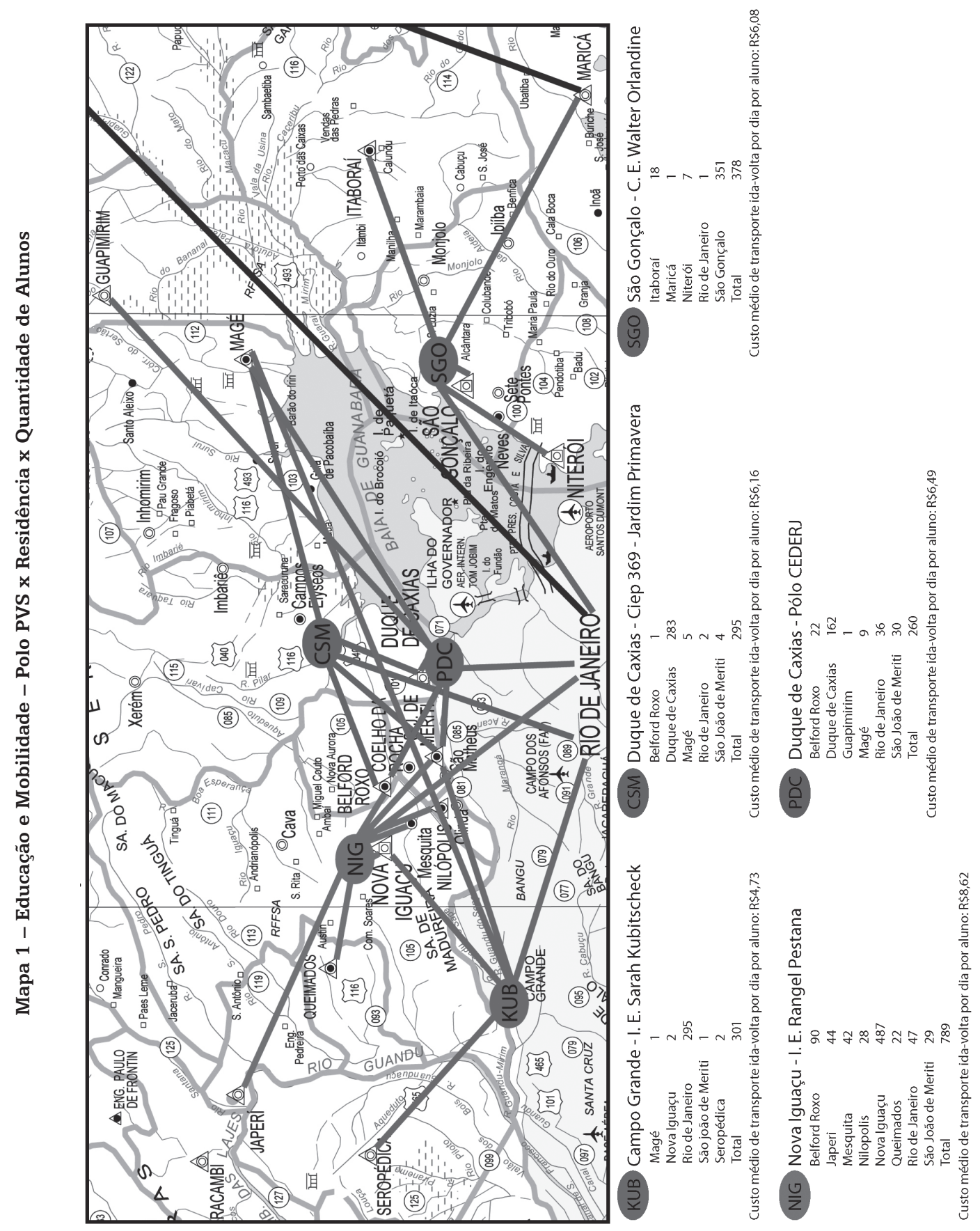
Os registros propiciados por distintas avaliações realizadas no decorrer das atividades indicam uma estreita relação entre a capacidade de mobilidade dos alunos e o próprio sucesso do Programa, sobretudo no que se refere às suas possibilidades reais de ampliação. Aqui destacamos um problema que merece atenção para seu enfrentamento: a questão da evasão do curso. Entendemos que a evasão se configura como um fenômeno multifatorial, porém a ampliação e a melhoria dos serviços oferecidos pelo PVS, sobretudo no que se refere aos obstáculos à mobilidade e integração social e cultural, podem contribuir para o desenvolvimento do Programa e a maximização das possibilidades de sucesso dos alunos.

De acordo com Vasconcellos (2001, apud Gomide, 2003), a acessibilidade, medida mais direta dos efeitos de um sistema de transporte, pode ser vista como a facilidade de se atingir os destinos desejados. A acessibilidade pode ser avaliada pelo número e pela natureza dos destinos desejados a serem alcançados por uma pessoa, levando-se em conta o tempo e o custo necessários à sua realização. Na medida em que os serviços de transporte não são gratuitos, observa-se uma associação muito estreita entre mobilidade urbana e renda, ou seja: a renda familiar é determinante da mobilidade urbana. Na verdade, o depoimento de um tutor do Polo Duque de Caxias, em novembro de 2010, mostra como essa rede de situações de exclusão se perpetua caso não seja interrompida em seus múltiplos entroncamentos:

Um aluno da [turma] CCO1 chegou até mim para informar que uma aluna, [...], da mesma turma, havia dito que não iria fazer as provas da UFF e da UFRJ por estar sem dinheiro para a passagem. Diante de tal situação, pedi contribuição aos demais tutores para ajudá-la. A aluna já havia pedido dinheiro emprestado a vizinhos anteriormente para fazer o Enem. O fato gerou uma discussão entre os tutores e nos fez perceber que não temos noção da dimensão da pobreza em que se mergulham os alunos. Mesmo sabendo dessa realidade, através, por exemplo, das seleções, é difícil notar que, para as provas mais importantes para as quais o aluno se esforçou, um aspecto desse possa afundar o trabalho de um ano.

São frequentes os relatos de tutores sobre a ocorrência de abandono do curso relacionada à falta de recursos para cobrir os altos custos de transporte, especialmente os intermunicipais. Dois depoimentos de alunos registrados no Sistema de Avaliação dos Tutores e do Curso, em novembro de 2010, espelham a dificuldade de mobilidade também no interior do Estado e nos fazem supor que muitos, embora desejassem frequentar o curso, sequer chegam a se inscrever, diante da impossibilidade de arcar com os custos do transporte.

O PVS foi um curso excelente, o único agravante para mim e para outras pessoas foi a questão do transporte. A maioria dos alunos não reside em Santa Maria Madalena e esta não tem transporte com horários e preços adequados. Esse foi o grande motivo de outros alunos desistirem. Eu e outras 3 meninas só continuamos graças a tutora, que nos leva no carro dela. Outros não tiveram a mesma sorte e tiveram que abandonar. (Aluna do polo de Santa Maria Madalena, 18 anos) 
${ }^{16}$ O Estatuto da Criança e do Adolescente (ECA), que dispõe sobre a proteção integral à criança e ao adolescente, considera adolescente a pessoa entre 12 e 18 anos de idade.

${ }^{17}$ Segundo Vianna (2010), jovens que possuem entre 12 e 18 anos, do sexo masculino, de baixo poder aquisitivo, com histórico de acesso restrito aos meios fundamentais de sobrevivência (saúde, educação, lazer, cultura) e, em geral, residentes em favelas compõem atualmente, de forma quase absoluta, o perfil do contingente populacional atendido pelo Departamento Geral de Ações Socioeducativas (Degase). Embora o ECA reconheça este segmento da população como sujeito em peculiar condição de desenvolvimento, a quem devem ser assegurados os direitos de cidadania, sabemos que parte significativa deste segmento jovem, quando tem acesso restrito às políticas públicas, torna-se especialmente vulnerável e exposto a diferentes formas de risco.
Gostaria que houvesse um polo em Bom Jardim/RJ. Muitas pessoas de área rural poderiam estudar. Seria muito bom também que tivéssemos direito a um transporte gratuito. Já que o PVS é social, certamente não temos dinheiro todos os sábados para estudar. Eu, por exemplo, não tive. (Aluna do polo de Cantagalo, residente em Monnerat, distrito do município de Duas Barras, 26 anos)

Tanto a bibliografia que trata das expressões da questão social articuladas às condições de mobilidade da população nas grandes metrópoles quanto os dados disponíveis nos permitem reforçar a afirmação de que está em curso uma progressiva expulsão dos mais pobres do acesso aos serviços de transporte público coletivo nos principais centros urbanos brasileiros. Tal expulsão tem resultado, como visto, no agravamento da pobreza urbana e dos níveis de exclusão social no País.

Consideramos que a proposta de democratização do acesso à educação superior deve buscar medidas que corrijam as distorções do sistema educacional em seus mecanismos centrais vigentes. Assim, por coerência, tal proposta deve pautar-se em medidas não restritivas. Estratégias e instrumentos de inclusão podem ser múltiplos, mas devem buscar garantir a reversão das contradições e das condições de desigualdade observadas nessa área da dinâmica social. Nesse sentido, a extensão do subsídio que viabilize o transporte dos alunos vinculados ao PVS para a frequência ao curso e o seu deslocamento para a realização dos exames de ingresso às universidades e do Enem, além de tornar efetivo o acesso deste segmento a atividades culturais relevantes à complementação de sua formação educacional, é considerada como um investimento fundamental.

Sobretudo a implementação de políticas públicas dirigidas aos jovens é uma medida urgente, não apenas no sentido de reforçar e ampliar ações concretas que viabilizem a conquista de direitos reconhecidos no Estatuto da Criança e do Adolescente (ECA), ${ }^{16}$ mas também porque os desdobramentos e efeitos perversos das desigualdades sociais que rebatem neste segmento são hoje amplamente reconhecidos, seja através das denúncias de inserção precária e irregular desses segmentos no mercado de trabalho, seja por seus rebatimentos em situações que se destacam na área da segurança pública, haja vista o frequente envolvimento de jovens, inclusive de pequenas cidades, com o tráfico de drogas, ao mesmo tempo em que declina a frequência no ensino médio, sobretudo nos jovens do sexo masculino. ${ }^{17}$

Outra abordagem do problema nos remete à importância da dimensão cultural para o alargamento dos horizontes de estudo e trabalho dos alunos do PVS. Na era da globalização, a cultura, em sentido lato, adquire uma importância fundamental no acesso e ampliação do conhecimento, na medida em que tempo e espaço são redimensionados e, cada vez mais, as fronteiras do conhecimento são diluídas. Por outro lado, nesse mesmo contexto, observa-se uma competição crescente entre as nações e o mercado global, aliada à crescente crise econômica, o que pode contribuir para uma visão instrumental ou restrita da educação como simples reprodutora dos padrões dominantes. Defende-se a tese de que uma educação abrangente é necessária para formar cidadãos críticos. 
Vale ressaltar que, em grande parte, os alunos atendidos pelo PVS, apesar de terem acesso à Internet e outros meios de informação, encontram-se distantes, física e socialmente, de instituições ou espaços culturais, o que é dificultado ainda pela restrita capacidade de mobilidade, dadas as carências familiares e os problemas da rede de transportes públicos no Estado. Conforme ressaltamos no item anterior, em função de um dos critérios de elegibilidade para o Programa referir-se à renda per capita familiar, os alunos do PVS integram, em sua maioria, exatamente o contingente de menor renda da população. Assim, 87\% dos alunos do PVS apresentavam em 2009 renda per capita familiar igual ou inferior a R\$ 630,00, índice que se manteve em 2010.

Exatamente no sentido de alargar o horizonte cultural de seu público, no ano de 2010 o PVS incentivou e muitos tutores, assumindo o papel de orientadores, tomaram algumas iniciativas. Foram organizadas visitas em grupo a museus no centro da capital do Estado, a laboratórios e aos campi de universidades e a participação na Jornada de Iniciação Científica da Fiocruz. A visita ao Museu da Língua Portuguesa, em São Paulo, realizada em novembro de 2010, foi programada pela Direção do PVS para os tutores que ministram aulas de Língua Portuguesa e Redação. Essas foram algumas das atividades pedagógicas desenvolvidas pelo PVS visando o desenvolvimento de alunos e tutores.

Dessa forma, defendemos que a ampliação e melhoria dos serviços oferecidos pelo PVS, enquanto medidas aliadas a ações que articulam o enfrentamento das desigualdades e contradições sociais expressas em distintas áreas da vida social e da dinâmica urbana, podem contribuir para o desenvolvimento do Programa e a maximização das possibilidades de sucesso dos alunos, sobretudo no enfrentamento imediato dos obstáculos à integração social e cultural.

\section{Conclusão}

Os aspectos analisados ao longo do texto nos permitem afirmar a importância do Pré-Vestibular Social enquanto ação que tem por objetivo contribuir para a democratização do acesso à universidade e estender essa oportunidade aos moradores do interior do Estado do Rio de Janeiro, afastados dos centros que dispõem de serviços mais estruturados, assim como para as camadas de baixo poder aquisitivo da região metropolitana.

O sentido mais amplo dessa ação se fortalece no contexto das mudanças impulsionadas pela reestruturação produtiva da economia globalizada, que desencadeou uma maior valorização do trabalho intelectual e das capacidades inovadoras e integradoras que ele permite, colocando em evidência a necessidade de uma formação continuada, diversificada, dinâmica e de qualidade. Além disso, em países marcados por contradições sociais profundas e sobrepostas que revelam uma 
complexa relação entre níveis e formas de inclusão/exclusão - como é o caso do Brasil -, frequentemente observamos a privação de direitos constitucionais, especialmente quando se trata dos setores de menor poder aquisitivo. Nesse sentido, entendemos ser de fundamental importância o desenvolvimento de ações educativas que favoreçam a permanência e a qualidade da aprendizagem de alunos de baixa renda, para que possam se inserir no sistema educacional em todos os níveis hoje oferecidos, inclusive no universitário.

Ao longo de sua trajetória, o Pré-Vestibular Social tem progressivamente mobilizado diversas alternativas visando ampliar e aprimorar o atendimento que presta a sua população-alvo. Isso tem acarretado o aumento do número de polos em diferentes municípios, a melhoria da infraestrutura já existente e medidas diversas voltadas para capacitar alunos e tutores. Conforme destacado nas reflexões apresentadas, o estudo sistemático do perfil de seus usuários tem permitido a identificação de entraves à realização das condições mínimas necessárias para a consecução do Programa, como aqueles relacionados às condições de mobilidade, que incidem na significativa evasão de seus alunos, sobretudo entre aqueles com idade até 24 anos, e restringem as possibilidades de ampliação de seus horizontes culturais. Entretanto, os limites impostos por essas condições não têm impedido que alunos que permanecem no PVS alcancem seus objetivos mais imediatos de inserção no ensino superior, expressos nos índices de aprovação nos vestibulares anteriormente apontados.

Os resultados positivos obtidos pelo Programa, ainda que restrito ao Estado do Rio de Janeiro, reforçam a importância da ampliação dos investimentos públicos na área da educação em todos os níveis. Isso é essencial para enfrentar as defasagens encontradas no sistema educacional brasileiro, que revelam as múltiplas dimensões que o fenômeno da exclusão alcança em nosso país. Nesse sentido, entendemos que o Estado não pode abdicar de seu papel na garantia desse direito básico de cidadania, devendo fortalecer iniciativas que busquem enfrentar as desigualdades presentes em nossa realidade e que se expressam sobremaneira no campo da educação, sob pena de ter que arcar com graves consequências para a formação ética, política, social e cultural da população brasileira.

Assim, esperamos que este trabalho, ao analisar a experiência do PVS, possa contribuir para indicar diferentes alternativas para a inclusão social na área da educação, especialmente por meio de ações afirmativas que, nos dias atuais, se tornam cada vez mais necessárias, tendo em vista que se dirigem aos segmentos mais vulneráveis da população. O alargamento de possibilidades de inserção desses segmentos mediante ampliação e formulação de políticas públicas que visem democratizar as condições necessárias ao acesso à educação, sobretudo em espaços mal providos de equipamentos e serviços públicos, constitui-se, dessa forma, um requisito para a redução das desigualdades sociais constatadas em nosso País. 


\section{Referências bibliográficas}

BASTOS, M. D. F.; GOMES, M. F. C. M.; FERNANDES, L. L.

O Pré-Vestibular Social: desafios à busca da inclusão social. EaD

em Foco, Rio de Janeiro, v. 1, n. 1, p. 123-158, abr./out. 2010.

BRASIL. Constituição da República Federativa do Brasil, promulgada em 5 de outubro de 1988. São Paulo: Saraiva, 2003.

BRASIL. Lei no 9.394, de 20 de dezembro de 2006. Estabelece as Diretrizes e Bases da Educação Nacional. Diário Oficial de União, Brasília, DF, 23 dez. 1996. Disponível em: < www.planalto.gov.br >. Acesso em: 31 de março 2003.

BRASIL. Lei no 11.096, de 13 de janeiro de 2005. Institui o Programa Universidade para Todos - PROUNI, regula a atuação de entidades beneficentes de assistência social no ensino superior; altera a Lei n 10.891, de 9 de julho de 2004, e dá outras providências.

Diário Oficial da União, Brasília, 14 jan. 2005. Disponível em:

<www.planalto.gov.br/ccivil_03/_ato2004.../2005/Lei/L11096.htm>.

BRAZ DE CARVALHO, J. C. Os cursos pré-vestibulares comunitários e seus condicionantes pedagógicos. Cadernos de Pesquisa, v. 36, n. 128, p. 299-326, maio/ago. 2006.

CARVALHO, J. M.; GRIN, M. Universidade pública: elitista? Ciência Hoje, Rio de Janeiro, v. 34, n. 203, p. 16-20, abril 2004.

CASTRO, J. A.; AQUINO, L. M. C.; ANDRADE, C. C. (Orgs.). Juventude e políticas sociais no Brasil. Brasília: Ipea, 2009.

CONCEIÇÃO, W. S.; CUNHA, N. V. Trajetórias de jovens de periferia rumo à carreira universitária: mobilidade social, identidades e conflitos. O Social em Questão, v. 23, p. 93-112, 2010.

GOMIDE, A. A. Transporte urbano e inclusão social: elementos para políticas públicas. Brasília: Ipea, 2003. (Texto para discussão nº 960).

HARVEY, D. A condição pós-moderna. São Paulo: Loyola, 1992.

INSTITUTO DE PESQUISA ECONÔMICA APLICADA (Ipea). Pnad 2009: primeiras análises - situação da educação brasileira, avanços e problemas. Comunicados do Ipea, n. 66. Brasília: Ipea, nov. 2010. Disponível em: $<$ forumeja.org.br/am/sites/forumeja.org.br.am/files/ipea2.pdf>

KOWARICK, L. A espoliação urbana. Rio de Janeiro: Paz e Terra, 1979. 
MAGALHÃES, Sérgio. Novo fenômeno urbano. O Globo, 20 nov. 2010. Disponível em: <http://cidadeinteira.blogspot.com/2010_11_01_ archive.html >. Postado em: 21 nov. 2010.

MARTINS, J. S. Exclusão e a nova desigualdade. São Paulo: Paulus, 1997.

NASCIMENTO, A.; IGNACIO, J.; PINHEIRO, F. Das ações afirmativas dos movimentos sociais às políticas públicas de ação afirmativa: o movimento dos cursos pré-vestibulares populares e a democratização do ensino superior. O Público e o Privado, Fortaleza, n. 3, p. 189-205, jan./jun. 2004 .

OLIVEIRA, F. Crítica à razão dualista: o ornitorrinco. São Paulo: Boitempo, 2003.

RIBEIRO, Ana Clara Torres. Território usado e humanismo concreto: o mercado socialmente necessário. In: SILVA, C. A. et al. Formas em crise: utopias necessárias. Rio de Janeiro: Arquimedes, 2005.

RIBEIRO, Luiz Cesar de Queiroz. Dos cortiços aos condomínios fechados: as formas de produção da moradia na cidade do Rio de Janeiro. Rio de Janeiro: Civilização Brasileira, Ippur, UFRJ-Fase, 1997.

RIO DE JANEIRO (Estado). Lei no 4.151, de 4 de setembro de 2003. Institui nova disciplina sobre o sistema de cotas para ingresso nas universidades públicas estaduais e dá outras providências. 2003. Disponível em: < http://alerjln1.alerj.rj.gov.br/contlei.nsf/ b24a2da5a077847c032564f4005d4bf2/e50b5bf653e6040983256d9c0 0606969?OpenDocument>.

SANTOS, Milton. A natureza do espaço: técnica e tempo, razão e emoção. São Paulo: Hucitec, 1996.

. O espaço dividido. São Paulo: Editora USP, 2004.

. O espaço do cidadão. São Paulo: Editora USP, 2007.

SOUZA, Wanderley de. O necessário estímulo à expansão do ensino superior. 2005. Disponível em: < http://noticias.universia.com.br/ destaque/noticia/2005/06/23/479503/necessario-estimulo--expansodo-ensino-superior.html > . Acesso em: 25 mar. 2011.

. Uma chance para os excluídos. 2006. Disponível em: <http:// www.ufcg.edu.br/prt_ufcg/assessoria_imprensa/mostra_noticia. php?codigo $=3443>$. Acesso em: 25 mar. 2011. 
TELLES, V. Pobreza e cidadania: precariedade e condições de vida. In: MARTINS, H. S.; RAMALHO, J. R. (Orgs.). Terceirização: diversidade e negociação no mundo do trabalho. São Paulo: Hucitec, CediNets, 1999.

VIANNA, R. M. Adolescência em favela: impactos da urbanização nas condições de vida da população de Praia da Rosa e Sapucaia. Trabalho apresentado na XXXII Jornada Giulio Massarani de Iniciação Científica, Artística e Cultural da UFRJ, Rio de Janeiro, 2010.

Maria Durvalina Fernandes Bastos, doutora em Serviço Social pela Pontifícia Universidade Católica de São Paulo (PUC-SP), é professora aposentada da Escola de Serviço Social da Universidade Federal do Rio de Janeiro (UFRJ) e diretora do Pré-Vestibular Social da Fundação Centro de Ciências e Educação Superior a Distância do Estado do Rio de Janeiro (Cecierj).

mariabastos2008@gmail.com

Maria de Fátima Cabral Marques Gomes, doutora em Serviço Social pela Pontifícia Universidade Católica de São Paulo (PUC-SP), é professora titular da Escola de Serviço Social da Universidade Federal do Rio de Janeiro (UFRJ).

fcmgomes@gmail.com

Lenise Lima Fernandes, doutora em Planejamento Urbano e Regional pelo Instituto de Pesquisa e Planejamento Urbano e Regional (Ippur/UFRJ), é professora adjunta da Escola de Serviço Social da Universidade Federal do Rio de Janeiro (UFRJ).

leniself@uol.com.br

Bruno Alves de França, doutorando em Serviço Social pela Escola de Serviço Social da UFRJ, é mestre em Planejamento Urbano e Regional pelo Instituto de Pesquisa e Planejamento Urbano e Regional (Ippur/UFRJ).

bruno.seso@gmail.com

Recebido em 19 de abril de 2011.

Aprovado em 8 de fevereiro de 2012. 